\title{
Research on Upgrading Tactics of Tourism Industry in Heilongjiang Province
}

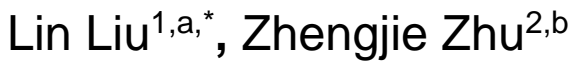 \\ ${ }^{1}$ Tourism and Cuisine School, Harbin University of Commerce, Harbin, China \\ ${ }^{2}$ Tourism and Cuisine School, Harbin University of Commerce, Harbin, China \\ aemail: bestlyn@163.com, bemai: 46652953@qq.com
}

Keywords: Industrial upgrading, Tourism product, All-for-one tourism.

\begin{abstract}
All-for-one tourism refers to a new tourism industry pattern which keeps the original value and functions of ecology, agriculture and culture while attaching the function of tourism consumption experience. As to Heilongjiang province, it is necessary to have deep development of original tourism products, such as ice-snow tourism, ecological tourism and border tourism. And in order to realize the upgrading of tourism industry and all-for-one tourism in Heilongjiang province, it is better to integrate tourism industry elements, construct surrounding areas, promote smart tourism and so on.
\end{abstract}

\section{Introduction}

Nowadays, people have more demands for spiritual entertainment and leisure with the growth of world economy and the development of society. Global tourism market grows rapidly and tourism industry becomes an important way of developing economy, promoting employment, improving people's livelihood and propagating of cultural concept. Tourism industry is the strategic emerging industry in Heilongjiang province. It promotes sound and rapid economic and social development in Heilongjiang province which consolidates and improves its status of major tourism province. In 2015, there are 130 million tourists from home and abroad with year-on-year growth of $21.89 \%$ and tourism income comes to 136.143 billion yuan with year-on-year growth of $27.7 \%$. But comparing with the developed areas, there are several serious problems in Heilongjiang province such as ignoring the improvement of consumption structure, paying the only attention to tourism arrivals, lacking of cultural connotation, insufficient regional cooperation and unbalanced regional development, lagging of management system, etc. Therefore, it is extremely urgent to upgrade tourism industry in Heilongjiang province. It is an inevitable option for the development of the tourism industry.

\section{Advantages of developing all-for-one tourism in Heilongjiang province}

Heilongjiang province is located in the northeast frontier and covers a vast geographic area. The advantages of tourism resources and location conditions may promote the realization of all-for-one tourism in Heilongjiang province.

\subsection{Better transportation condition}

Heilongjiang province is the transportation junction between three provinces in the northeast of China and Russian Far East. There are 11 major airports which attract tourists from Korea, Japan, Russia and the United States. Meanwhile, three feeder airports are under construction. The above may form a 2-hour tourism circle effectively. The CRH trains between Harbin and Qiqihar, Harbin and Mudanjiang will start running successively which enhance tourism convenience vastly.

\subsection{Unique tourism resource}

Heilongjiang province is located in mid-temperate zone with continental monsoon climate. Here the spring and autumn seasons are shorter while the winter season is at least five months. So it is a good place to spend holidays in the cooler summer and enjoy hunting and skiing in cold winter. The unique natural climatic condition in Heilongjiang province makes distinct and special seasonal scenery. 
Besides, Heilongjiang province borders on Russia, having rich historical multi-culture heritage. So it becomes the landmark of northeast tourism in China. And it has the potential of being a comprehensive reform demonstration zone of international tourism cities and tourism center of Northeast Asia tourism.

\subsection{Favorable policy support}

Recently, the strategy of developing tourism industry in Heilongiiang province relies on government-dominated and high-quality tourism products taking the lead. It regards scientific outlook on development as guidance, tourism resources as the basis and market needs as the direction. The regional support policy plays an important role in improving the environment of tourism development. And the increasing government support is on putting forward tourism industry as the leading one of the tertiary industry which speeds up the development of the whole tertiary industry. On the other hand, good news also offers favorable condition. A series of proper publicity make the overall tourism image known at home and abroad. Increasing popularization and application of information technology improves tourism accessibility and convenience significantly. The establishment of tourism development committee in Heilongjiang province provides institutional guarantee for upgrading of tourism industry. All these factors provide favorable conditions for the transformation and upgrading of tourism industry in Heilongjiang province.

\section{Upgrading tactics of tourism industry in Heilongjiang province}

\subsection{All-for-one tourism industry construction}

All-for-one tourism is a complex industry system including tourism industry, national culture industry, health service industry, manufacturing industry and service industry on production and consumption. Tourism needs is the key point and the consumption is the main direction. The integration of elements related to other industries is the important method while effectively matching demand and supply is the ligament. And the win-win development of market subjects is the motivation. The following are the ways to promote the construction of all-for-one tourism. Firstly, the integration of tourism development and small town construction should be accelerated. Make the small town which is suitable for living, sightseeing and doing business with good environment, charming scenery, distinct features and multiple functions. Secondly, the profound integration of tourism industry and culture industry should be accelerated. Tourism industry may be integrated with TV program and movie, performance, festivals, animation and Internet literature. Thirdly, the integration of tourism industry, the primary industry, the secondary industry and tertiary industry should be accelerated. For example, we may design tourism products with experiences of picking fruits and vegetables, enjoying ecological scenery or lodging with locals. We may establish some enterprises and plan industrial tourism area to develop tourism products manufacturing industry. And we may enhance the integration of tourism industry and medical, sports, commerce, telecommunications and elderly care service industry. Fourthly, the integration of tourism development and ecological construction should be accelerated. The construction of pilot national park and pilot area of ecological tourism also need to be accelerated. It's better to form a well-behaved interactive mechanism of tourism development and ecological environment protection. Fifthly, the integration of tourism development and rural area construction should be accelerated. Promote the construction of recreational zone between urban and rural area and enrich the content of sightseeing. Explore the new method of the overall planning for urban-rural development on the basis of new rural area construction. Sixthly, the integration of tourism development and implement of opening to the outside world should be accelerated. The location of Heilongjiang province is good for it is the center of Russia Far East area. With the functions of national ports such as Suifenhe, Dongning, Heihe, Fuyuan and Harbin ports, try to make Heilongjiang province an economic cooperation area of border tourism development. 


\subsection{Scientific planning system}

The key point of industry development is scientific tourism planning layout. The combination of government requirements on scientific tourism planning layout and the importance of market to allocation of resources may promote tourism development in Heilongjiang province. Administrative departments at all levels need to supervise the progress of provincial major tourism projects and put an end to homogenization development and low-level redundant development. It is necessary to facilitate synergetic and interactive development of regional tourism as a whole.

\subsection{Coordinated regional development}

Tourism management space in Heilongjiang province needs to transform from local development to national or international development. It is better to establish a northeast tourism zone which covers Heilongjiang province, Jilin province, Liaoning province and Inner Mongolia in order to promote regional tourism economy cooperation. In addition, it is a must to cooperate whole heartedly with related tourism administration and travel agencies in with Russia, Japan, South Korea, North Korea, Mongolia and other countries for attracting more tourists.

\subsection{Integration of tourism industry elements}

The emphasis of tourism development is transforming from specific scenic spots to tourism zone. And in-depth tour of one destination is taking place of traditional desultory sightseeing. So the strategy of affecting center factors, stimulating core factors, promoting border factors and interacting the overall factors should be carried out. First, the strategy of stimulating polar tour needs to be implemented. There is monopolistic advantage of tour to the north and east pole in China. The construction of these two core scenic spots may motivate long-distance tour development by connecting other scenic spots on the way. Second, the strategy of developing border tour needs to be implemented. And the emphasis could be on Heilongjiang River, Wusuli River, Xingkai Lake and border ports. Then it is easier to develop boundary river tour, boundary lake tour and border tour as well in Suifenhe and Dongning. Third, the leading strategy of tourism development in Harbin needs to be implemented. Harbin is the hub of circum as tourism destination, tourist generating region and transit center. Fourth, the strategy of regional interaction needs to be implemented. Tourism products in each city should be promoted as a whole in order to realize benefits-sharing and win-win situation.

\subsection{Expansion of customer market}

Create the overall image of Heilongjiang province on magnificent northern scenery with the aim of specialization, branding and internationalization. Further intensify tourism promotion according to different customers, such as businessman, the middle and the old, office workers and the young separately. Exploit customer markets not only in northeast region, Beijing-Tianjin-Tangshan area, Southeast coastal area of China as well as Russia, Japan, Korea, Hong Kong, Macao and Taiwan but also in Chinese Midwest, Europe and the United States. And tourism marketing strategy should be diverse. We need to combine administrative promotion with enterprise marketing, online marketing with offline marketing and marketing to the experts with marketing to the public. Thus, we may further consolidate and develop important tourist market in Heilongjiang province.

\subsection{Promotion of smart tourism}

Science and technology supports tourism innovation and integration development. We should apply modern scientific and technological achievements to tourism industry development and set up professional tourism technology innovation platform. Taking good use of modern technology information to develop smart tourism vigorously, Smart tourism is a new kind which utilizes cloud computing, the Internet and other new technology to highly integrate tourism resources and information resources for tourism management and tourists. It is easier for them to learn related information and realize tourism experience, schedule planning, online settlement, industry supervision and safety guarantee by using portable internet-based devices. So it is necessary to 
establish database of tourism resource, construct mobile client side and "one-stop" service platform of smart tourism. Also we may try to explore the construction of smart city, smart scenic spot, smart hotel and smart travel agency for guiding tourism enterprises to utilize the Internet and cloud computing to perfect tourism information system planning.

\section{Acknowledgement}

This research was financially supported by young innovative talents support project of Harbin University of Commerce (Grant NO. 2016QN028), teaching reform and research project of Harbin University of Commerce (Grant NO. HSDJY09(Z) ) and 2015 young innovative talent cultivating of general undergraduate university in Heilongjiang Province (Grant NO.UNPYSCT-2015065), Project of philosophy and social science in Heilongjiang Province (Grant NO. 16JYE03), Discipline project of Harbin University of Commerce (Grant NO. hx2016001).

\section{References}

[1] Shang Xiaoli, Analysis on tourism professional group construction based on all-for-one tourism industry cluster, Guide to Business, vol.13, pp123-124, 2016.

[2] Dong Lin, Xu Shumei and Gao Yuan, Study on the Transformation and Upgrading of Tourism Industry in Heilongjiang Province,The Border Economy and Culture, vol.3, pp27-28, 2014.

[3] Li Jinzao, The connotation of all-for-one tourism, West China Development, vol. 11, pp. 101-102, 2016. 